\title{
KINERJA KOORDINASI SIMPANG BERSINYAL JALAN RAJAWALI - JALAN GARUDA (SIMPANG I) JALAN RAJAWALI - JALAN TINGANG (SIMPANG II) KOTA PALANGKA RAYA
}

\author{
Muhammad Ikhsan Sidiq ${ }^{1}$ \\ ${ }^{1}$ Dinas Perhubungan Komunikasi dan Informatika Provinsi Kalimantan Tengah
}

\begin{abstract}
ABSTRAK
Ruas Jalan Rajawali merupakan ruas Jalan Kolektor dimana sepanjang jalan terdapat banyak Pertokoan, Sekolah, Puskesmas, Hotel dan Perumahan Penduduk. Pada ruas Jalan Rajawali terdapat 2 (dua) titik simpang bersinyal empat lengan dimana jarak antara kedua titik persimpangan yaitu 540 meter. Kedua simpang yang berdekatan yaitu Jalan Rajawali dan Jalan Garuda (simpang I) serta Jalan Rajawali dan Jalan Tingang (simpang II). Penelitian memiliki tujuan untuk mengetahui kinerja Simpang I dan Simpang II pada kondisi eksisting dan memberikan pilihan solusi agar tingkat pelayanan kedua simpang bersinyal menjadi lebih baik. Pengambilan data primer dilakukan dengan obeservasi langsung dilapangan, komponen data yang diambil melalui observasi berupa volume lalu lintas simpang, Geometrik simpang, dan waktu siklus. Sedangkan dalam melakukan perhitungan untuk mengetahui kinerja pada Simpang I dan Simpang II dilakukan dengan pendekatan MKJI. Solusi yang diterapkan untuk meningkatkan pelayanan pada kedua kinerja simpang dengan cara merubah fase pada kedua simpang kemudian dilakukan koordinasi sinyal pada kedua simpang secara manual. Hasil kinerja pada kondisi eksisting jam puncak siang menunjukkan nilai tundaan tertinggi di simpang I sebesar 78,79 det/smp dengan tingkat pelayanan E, sedangkan pada simpang II nilai tundaan sebesar 47,71 detik dengan nilai Indeks Tingkat Pelayanan E untuk jam puncak siang. Setelah dilakukan Skenario koordinasi sinyal dengan menyamakan kedua fase yaitu 3 fase serta perubahan waktu siklus pada Simpang I selama 50 detik dan Simpang II selama 50 detik, diperoleh nilai tundaan rata-rata pada simpang I sebesar 27,38 det/smp dengan nilai pelayanan D untuk jam puncak siang dan simpang II sebesar 30,30 det/smp dengan nilai pelayanan D. Penerapan koordinasi sinyal antara Simpang I dan Simpang II telah memaksimalkan kinerja simpang serta tingkat pelayanan pada Simpang I dan Simpang II menjadi lebih baik.
\end{abstract}

Kata Kunci: waktu siklus, tundaan, tingkat pelayanan, koordinasi simpang bersinyal

\section{PENDAHULUAN}

Ruas Jalan Rajawali di Kota Palangka Raya terdapat di Kecamatan Jekan Raya dengan panjang jalan $6,5 \mathrm{~km}$, lebar jalan pada titik lokasi 6 meter, terbagi 2 lajur 2 arah tanpa median (2/2 UD). Ruas Jalan Rajawali merupakan kawasan permukiman, pertokoan dan terdapat fasilitas umum seperti sekolah, puskesmas, perkantoran serta tempat ibadah, pada ruas jalan ini terdapat dua titik simpang bersinyal berdekatan dengan jarak 540 meter yaitu pada persimpangan Jalan Rajawali dengan Jalan Garuda (simpang I) dan persimpangan Jalan Rajawali dengan Jalan Tingang (simpang II), kedua simpang memiliki jarak yang dekat sehingga

Correspondence: Muhammad Ikhsan Sidiq

Email : ikhsan28dishidiq@gmail.com
Menyebabkan pengendara mendapatkan berhenti pada simpang berikutnya, tentunya hal ini sangat berdampak terhadap tingkat pelayanan ruas jalan dan simpang.

Pada hari Senin merupakan hari sibuk, arus lalu lintas pada jam puncak pagi, siang maupun sore di persimpangan ini cukup tinggi dengan jam sibuk pada pagi hari pukul 06.00 - 08.00 WIB, Jam sibuk siang pukul $11.00-$ 13.00 WIB dan jam sibuk sore pada pukul 16.00 - 18.00 WIB. Kondisi pada saat jam sibuk pengguna kendaraan bermotor bisa terkena dua kali merah pada titik lokasi simpang bersinyal yang sama, hal ini disebabkan karena adanya penumpukkan antrian pada simpang tersebut. 


\section{METODE PENELITIAN}

Pada metode penelitian di awali dengan pengumpulan data sekunder terlebih dahulu, adapun data-data sekunder yang dibutuhkan pada penelitian ini yaitu:

1. Jumlah penduduk;

2. Peta jaringan jalan;

3. Peta batas administrasi;

4. Status jalan;

5. Tahun pembuatan alat persinyalan simpang.

Bagan alir evaluasi kinerja simpang lebih jelasnya dilihat pada Gambar 1. Adapun bagan AlurPenelitian dapat dilihat pada Gambar 2.
Kemudian tahap selanjutnya dilakukan pengambilan data primer dengan melakukan pengamatan langsung dilapangan (survei). Adapun metode pengambilan data dilapangan sebagai berikut:

1. Survei geometrik simpang.

2. Survei volume lalu lintas dipersimpangan.

3. Survei waktu siklus.

4. Survei waktu tempuh.

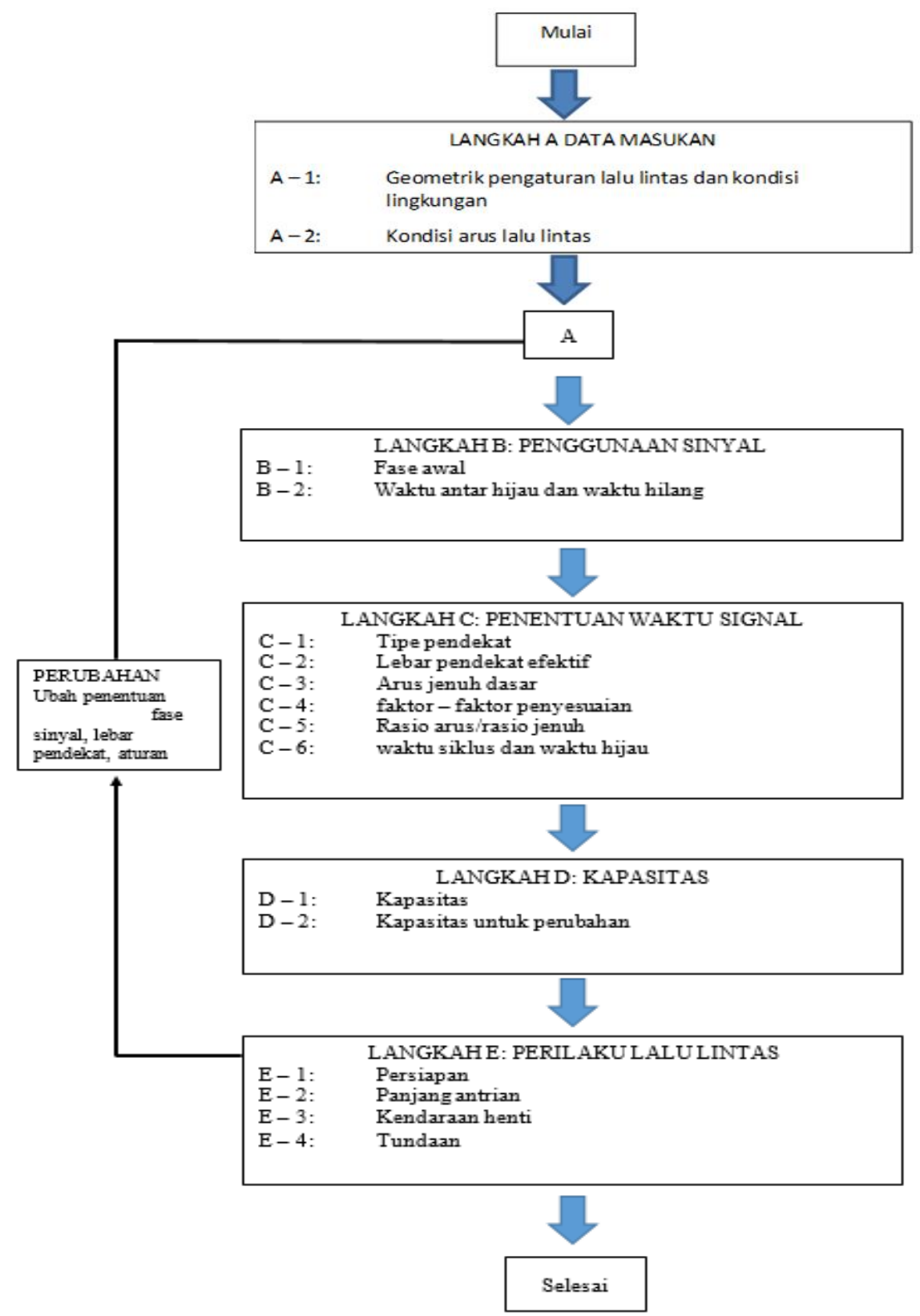

Gambar 1. Tahap Evaluasi Kinerja Simpang Berdasarkan Manual Kapasitas Jalan Indonesia, Toha 1997 
Muhammad Ikhsan Sidiq

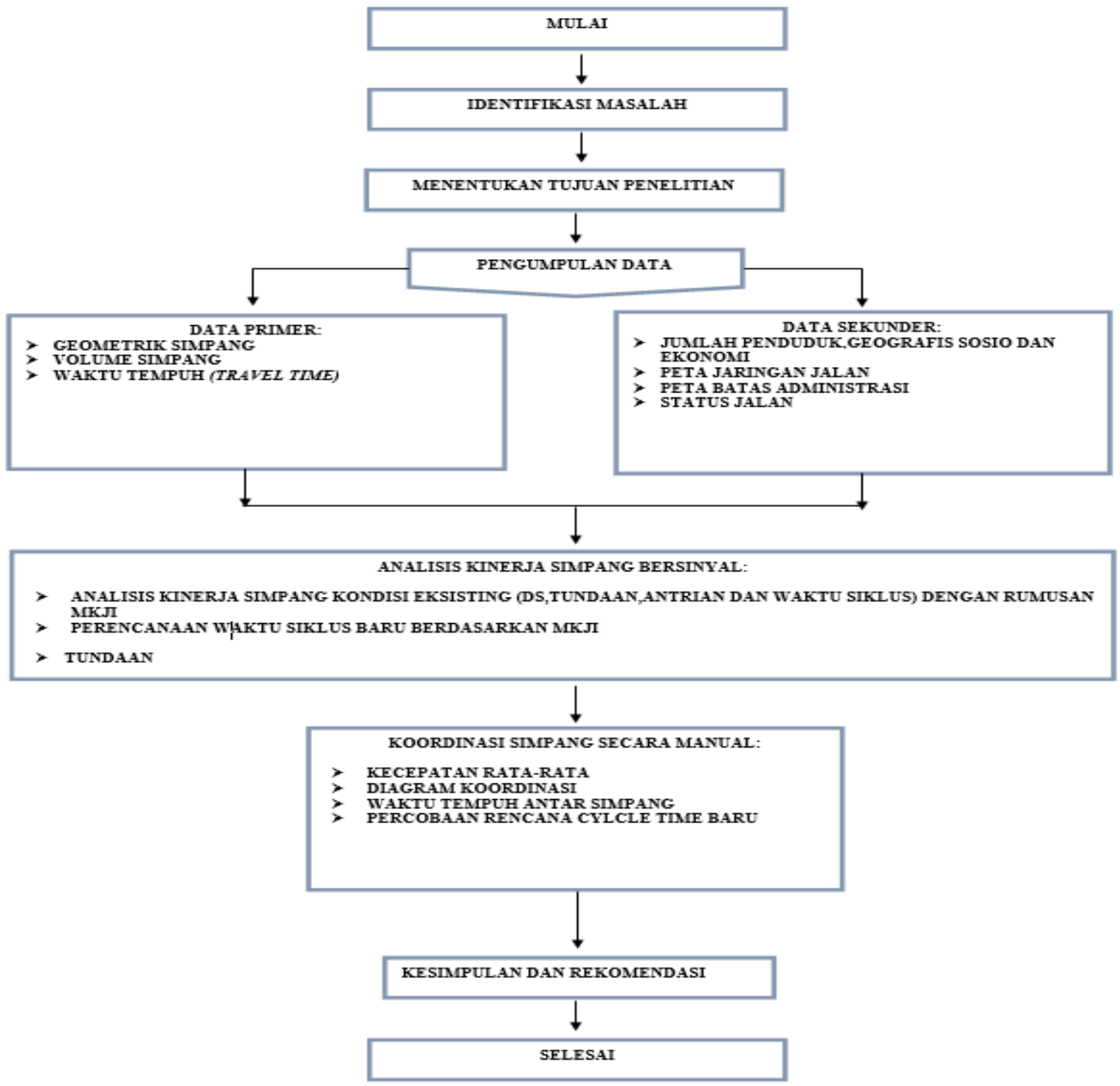

Gambar 2. Bagan Alur Penelitian

\section{HASIL DAN PEMBAHASAN}

\subsection{Kinerja Simpang Bersinyal Kondisi Eksisting}

Pada kondisi eksisting diketahui Geometrik Simpang I dan Simpang II sebagai

komponen dalam menganalisis kinerja simpang bersinyal. Hasil pengukuran geometrik simpang pada Simpang I dan Simpang II dapat dilihat pada Tabel 1 berikut ini.

Tabel 1. Geometrik Simpang

\begin{tabular}{clccc}
\hline \multirow{2}{*}{ Lokasi } & \multicolumn{1}{c}{ Pendekat } & $\begin{array}{c}\mathrm{W}_{\mathrm{A}} \\
(\mathrm{m})\end{array}$ & $\begin{array}{c}\text { Lebar pendekat } \\
\mathrm{W}_{\text {masuk }} \\
(\mathrm{m})\end{array}$ & $\begin{array}{c}\mathrm{W}_{\text {keluar }} \\
(\mathrm{m})\end{array}$ \\
\hline \multirow{3}{*}{ Simpang I } & Utara & 3,0 & 3,0 & 3,0 \\
& Timur & 6,9 & 6,0 & 4,0 \\
& Selatan & 3,0 & 3,0 & 3,0 \\
& Barat & 4,0 & 4,0 & 5,9 \\
& Utara & 3,0 & 3,0 & 3,0 \\
& Timur & 4,0 & 4,0 & 4,0 \\
& Selatan & 3,0 & 3,0 & 3,0 \\
& Barat & 4,0 & 4,0 & 4,0 \\
\hline
\end{tabular}


KINERJA KOORDINASI SIMPANG BERSINYAL JALAN RAJAWALI - JALAN GARUDA (SIMPANG I) JALAN RAJAWALI - JALAN TINGANG (SIMPANG II) KOTA PALANGKA RAYA Muhammad Ikhsan Sidiq

Sedangkan untuk Gambaran geometrik Gambar 3 dan Gambar 4 berikut ini. simpang bersinyal eksisting dapat dilihat pada

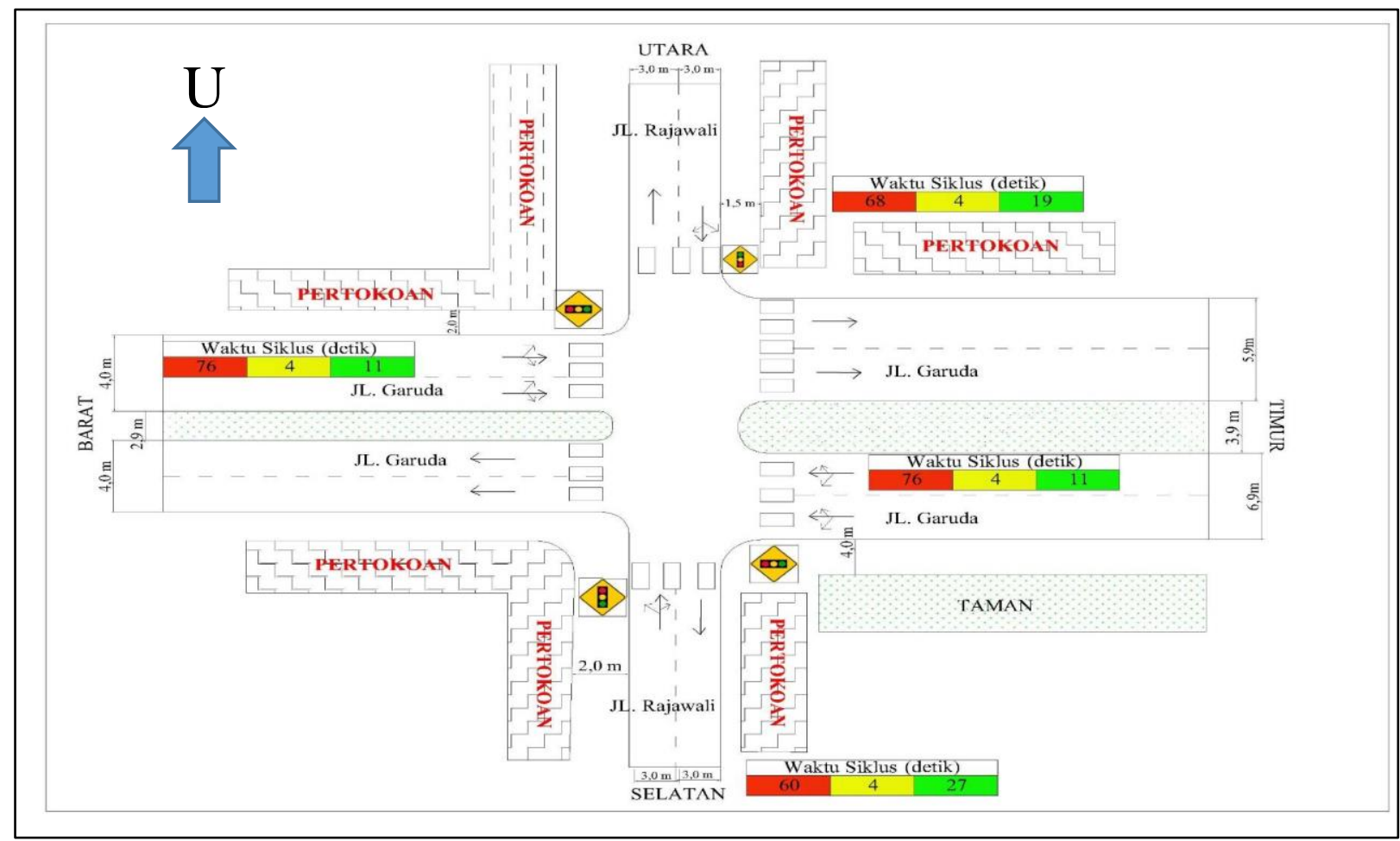

Gambar 3. Geometrik Eksisting Simpang I

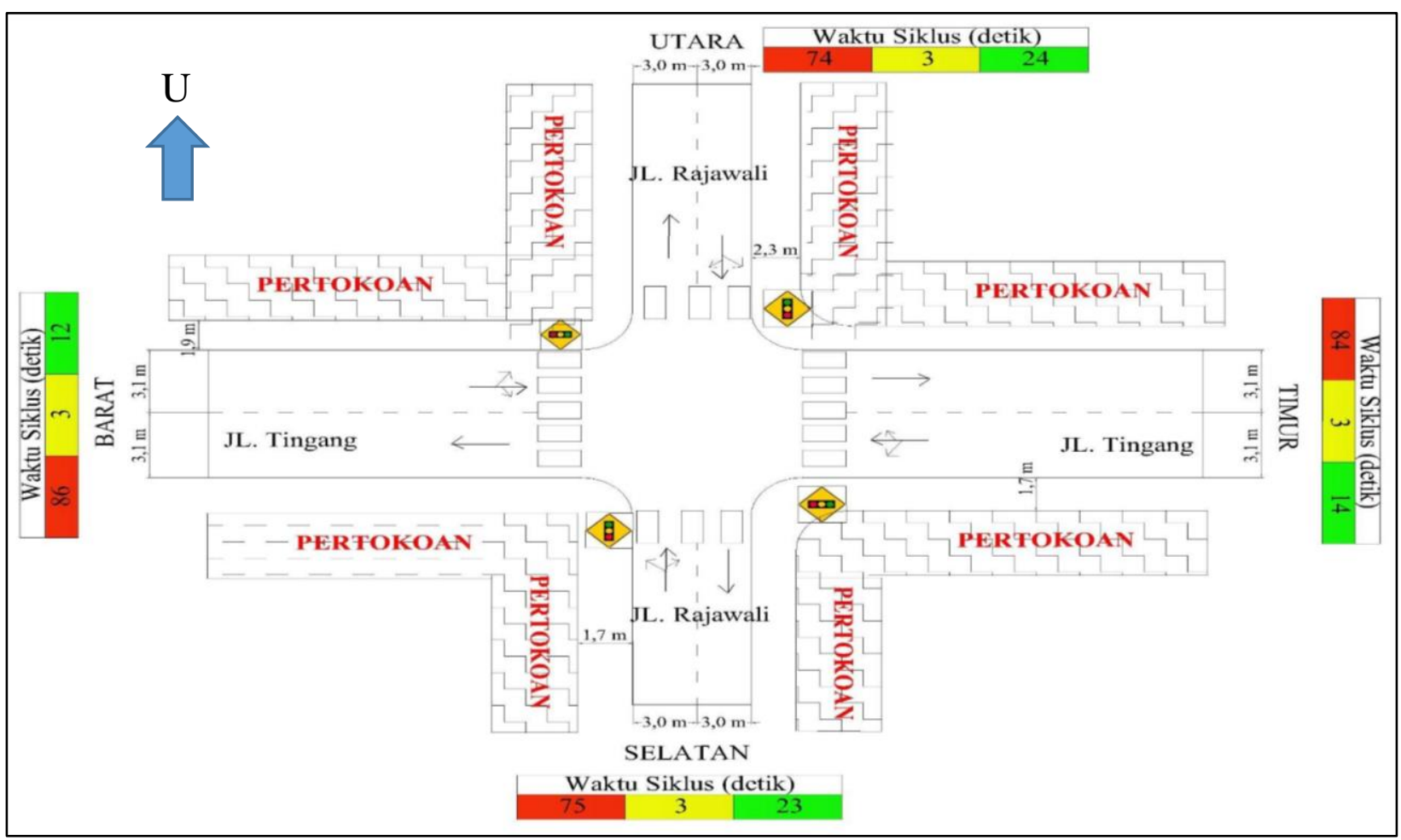

Gambar 4. Geometrik Simpang II

Terdapat 2 (dua) simpang bersinyal yang akan di koordinasikan, dari hasil pengambilan data waktu siklus eksisting serta fase simpang diperoleh waktu siklus yang berbeda antara kedua simpang. Adapun kondisi waktu siklus eksisting dapat dilihat pada Tabel 2. 
Muhammad Ikhsan Sidiq

Tabel 2. Waktu Siklus Eksisting

\begin{tabular}{|c|c|c|c|c|c|c|}
\hline \multirow{2}{*}{ Lokasi } & \multirow{2}{*}{ Pendekat } & \multicolumn{3}{|c|}{ Waktu Sinyal } & \multirow{2}{*}{$\begin{array}{c}\text { All } \\
\text { Red }\end{array}$} & \multirow{2}{*}{$\begin{array}{l}\text { Waktu } \\
\text { Siklus }\end{array}$} \\
\hline & & Merah & Kuning & Hijau & & \\
\hline Simpang I & Utara & 68 & 4 & 19 & 1 & 92 \\
\hline Jl. Rajawali - Jl. & Selatan & 60 & 4 & 27 & 1 & 92 \\
\hline \multirow[t]{2}{*}{ Garuda } & Timur & 76 & 4 & 11 & 1 & 92 \\
\hline & Barat & 76 & 4 & 11 & 1 & 92 \\
\hline \multirow{4}{*}{$\begin{array}{l}\text { Simpang II } \\
\text { J1. Rajawali - Jl. } \\
\text { Tingang }\end{array}$} & Utara & 74 & 3 & 24 & 2 & 103 \\
\hline & Selatan & 75 & 3 & 23 & 2 & 103 \\
\hline & Timur & 84 & 3 & 14 & 2 & 103 \\
\hline & Barat & 86 & 3 & 12 & 2 & 103 \\
\hline
\end{tabular}

Sedangkan untuk fase pada kedua simpang memiliki fase yang sama yaitu menggunakan jenis 4 fase, gambar fase eksisting dapat dilihat pada Gambar 5 dan Gambar 6 dibawah ini.
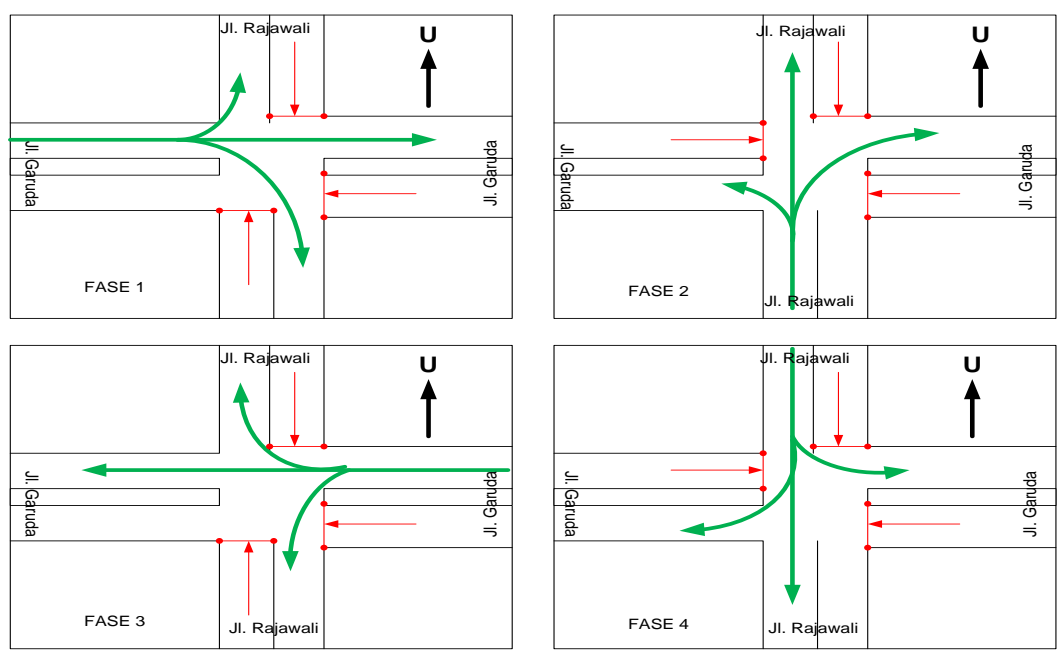

Gambar 5. Fase Eksisting Simpang I
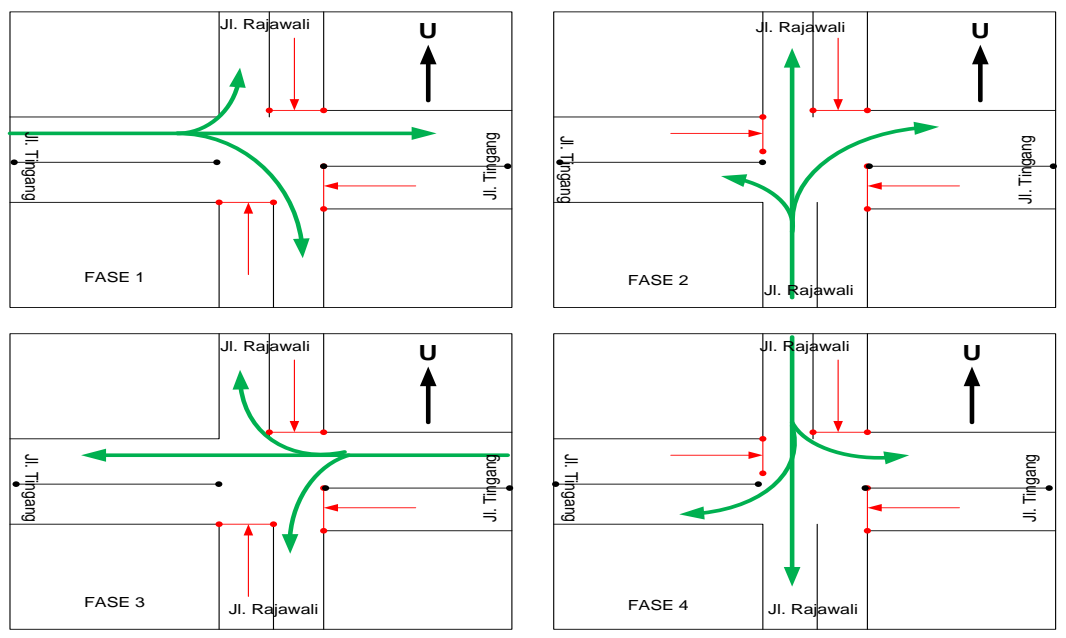

Gambar 6. Fase Eksisting Simpang II

Diketahui waktu tempuh antara kedua simpang selama obaservasi dilapangan pada jam sibuk siang yaitu selama 56 detik.

Survei volume lalu lintas simpang dilakukan dalam satu hari yaitu pada hari Senin tanggal 24 Oktober 2016. Jam sibuk

yang di jadikan sampel yaitu Jam sibuk pagi, jam sibuk siang dan jam sibuk sore. Survei dilaksanakan serentak pada kedua simpang untuk mendapatkan kondisi yang sama. Hasil rekapitulasi volume lalu lintas terdapat pada Tabel 3.

Jurnal Teknologi Berkelanjutan (Sustainable Technology Journal) Vol. 7 No. 1 (2018) pp. 52-64 
Tabel 3. Rekapitulasi Volume Lalu Lintas

\begin{tabular}{cccc}
\hline Lokasi & $\begin{array}{c}\text { Waktu } \\
\text { puncak }\end{array}$ & $\begin{array}{c}\text { Volume Jam Puncak } \\
\text { (kend/jam) }\end{array}$ & Ranking \\
\hline Simpang I & Pagi & 2678 & 2 \\
Jl. Rajawali - Jl. Garuda & Siang & 3657 & 1 \\
& Sore & 2403 & 4 \\
Simpang II & Pagi & 1965 & 6 \\
Jl. Rajawali - Jl. Tingang & Siang & 2121 & 5 \\
& Sore & 2494 & 3 \\
\hline
\end{tabular}

Dari hasil survei diketahui volume lalu lintas puncak pada simpang I yaitu jam sibuk siang dengan volume 3675 kendaraan/jam. Volume pada Jam puncak siang akan digunakan untuk koordinasi simpang.
Analisis kinerja simpang bersinyal pada kondisi eksisting dengan metode MKJI, diketahui kinerja pada Simpang I dan Simpang II didapat seperti pada Tabel 5 dan Tabel 4 dengan tingkat pelayanan masing masing simpang.

Tabel 4. Kinerja Eksisting Simpang I

\begin{tabular}{|c|c|c|c|c|c|c|c|c|c|}
\hline $\begin{array}{c}\text { Jam } \\
\text { Puncak }\end{array}$ & Pendekat & $\begin{array}{c}Q \\
(\text { smp/ } \\
\text { jam) }\end{array}$ & $\begin{array}{c}C \\
\text { (smp/ } \\
\text { jam) }\end{array}$ & $D S$ & $N Q$ & $\underset{\text { (meter) }}{Q L}$ & $\begin{array}{c}N S \\
\text { (smp/ } \\
\text { jam) }\end{array}$ & $\begin{array}{c}D \\
\text { (dtk/ } \\
\text { smp) }\end{array}$ & $\begin{array}{c}\text { ITP } \\
\text { Simpang } \\
\text { Bersinyal }\end{array}$ \\
\hline \multirow{4}{*}{$\begin{array}{c}\text { Pagi } \\
06.00- \\
08.00\end{array}$} & Jl. Rajawali (U) & 412 & 526 & 0,783 & 10,6 & 114 & 0,933 & \multirow{4}{*}{48,67} & \multirow{4}{*}{$\mathbf{E}$} \\
\hline & Jl. Rajawali (S) & 321 & 409 & 0,783 & 8,7 & 98 & 0,987 & & \\
\hline & Jl. Garuda (T) & 287 & 366 & 0,783 & 8,2 & 41 & 1,041 & & \\
\hline & Jl. Garuda (B) & 242 & 309 & 0,783 & 7,0 & 63 & 1,059 & & \\
\hline \multirow{4}{*}{$\begin{array}{c}\text { Siang } \\
11.00- \\
13.00\end{array}$} & Jl. Rajawali (U) & 484 & 552 & 0,878 & 21,0 & 206 & 0,987 & \multirow{4}{*}{78,79} & \multirow{4}{*}{$\mathbf{F}$} \\
\hline & J1. Rajawali (S) & 479 & 546 & 0,878 & 20,9 & 204 & 0,989 & & \\
\hline & Jl. Garuda (T) & 354 & 403 & 0,878 & 16,6 & 73 & 1,067 & & \\
\hline & Jl. Garuda (B) & 300 & 342 & 0,878 & 14,4 & 111 & 1,088 & & \\
\hline \multirow{4}{*}{$\begin{array}{c}\text { Sore } \\
16.00- \\
18.00\end{array}$} & Jl. Rajawali (U) & 403 & 488 & 0,827 & 13,0 & 136 & 0,981 & \multirow{4}{*}{58,70} & \multirow{4}{*}{$\mathbf{E}$} \\
\hline & J1. Rajawali (S) & 445 & 538 & 0,827 & 14,1 & 145 & 0,961 & & \\
\hline & Jl. Garuda (T) & 299 & 362 & 0,827 & 10,5 & 49 & 1,066 & & \\
\hline & Jl. Garuda (B) & 281 & 340 & 0,827 & 9,9 & 81 & 1,067 & & \\
\hline
\end{tabular}

Diketahui kinerja kondisi eksisting pada Simpang I di jam sibuk pagi bernilai E, pada jam sibuk siang bernilai $F$ dan pada jam sibuk sore tingkat pelayanan simpang bernilai E. Kinerja kondisi eksisting Simpang II terdapat pada Tabel 5.

Tabel 5. Kinerja Eksisting Simpang II

\begin{tabular}{|c|c|c|c|c|c|c|c|c|c|}
\hline $\begin{array}{c}\text { Jam } \\
\text { Puncak }\end{array}$ & Pendekat & $\begin{array}{c}Q \\
(\mathrm{smp} / \\
\text { jam) }\end{array}$ & $\begin{array}{c}C \\
\text { (smp/ } \\
\text { jam) }\end{array}$ & $D S$ & $N Q$ & $\underset{\text { (meter) }}{Q L}$ & $\begin{array}{l}N S \\
\text { (smp/ } \\
\text { jam) }\end{array}$ & $\begin{array}{c}D \\
\text { (dtk/ } \\
\text { smp) }\end{array}$ & $\begin{array}{c}\text { ITP } \\
\text { Simpang } \\
\text { Bersinyal }\end{array}$ \\
\hline \multirow{4}{*}{$\begin{array}{c}\text { Pagi } \\
06.00- \\
08.00\end{array}$} & Jl. Rajawali (U) & 371 & 529 & 0,667 & 7,1 & 77 & 0,882 & \multirow{4}{*}{33,05} & \multirow{4}{*}{ D } \\
\hline & Jl. Rajawali (S) & 203 & 290 & 0,667 & 4,4 & 56 & 1,000 & & \\
\hline & Jl. Tingang (T) & 144 & 206 & 0,667 & 3,4 & 36 & 1,079 & & \\
\hline & Jl. Tingang (B) & 178 & 254 & 0,667 & 4,0 & 40 & 1,031 & & \\
\hline \multirow{4}{*}{$\begin{array}{c}\text { Siang } \\
11.00- \\
13.00\end{array}$} & Jl. Rajawali (U) & 311 & 406 & 0,765 & 7,9 & 91 & 0,979 & \multirow{4}{*}{39,74} & \multirow{4}{*}{ D } \\
\hline & J1. Rajawali (S) & 254 & 331 & 0,765 & 6,7 & 80 & 1,020 & & \\
\hline & Jl. Tingang (T) & 229 & 299 & 0,765 & 6,2 & 74 & 1,047 & & \\
\hline & Jl. Tingang (B) & 241 & 315 & 0,765 & 6,4 & 75 & 1,030 & & \\
\hline \multirow{4}{*}{$\begin{array}{c}\text { Sore } \\
16.00- \\
18.00\end{array}$} & Jl. Rajawali (U) & 259 & 341 & 0,760 & 6,7 & 80 & 1,013 & \multirow{4}{*}{45,34} & \multirow{4}{*}{$\mathbf{E}$} \\
\hline & J1. Rajawali (S) & 314 & 412 & 0,760 & 7,7 & 90 & 0,969 & & \\
\hline & Jl. Tingang (T) & 238 & 313 & 0,760 & 6,3 & 58 & 1,044 & & \\
\hline & Jl. Tingang (B) & 355 & 467 & 0,760 & 8,7 & 74 & 0,965 & & \\
\hline
\end{tabular}


Kinerja eksisting simpang II pada jam puncak pagi dan jam puncak siang memiliki nilai pelayanan $\mathrm{D}$, sedangkan pada jam puncak sore nilai pelayanannya E. Dari hasil kinerja eksisting pada kedua simpang diketahui nilai pelayanan terendah terdapat pada simpang I di saat jam sibuk siang dengan nilai tingkat pelayanan $\mathrm{F}$ dan tundaan mencapai 78,79 det/smp.

\subsection{Skenario Koordinasi Simpang}

Pada penelitian kali ini skenario perencanaan koordinasi simpang bersinyal menggunakan metode manual sebagai berikut:

a. Tahap perencanaan fase baru.

Fase pada kondisi eksisting diperlukan perubahan, hal ini dikarenakan tingkat pelayanan simpang menggunakan fase eksisting bernilai E dan F. Perencaan fase baru yang diterapkan yaitu perubahan dari 4 fase menjadi 3 fase pada simpang I dan simpang II, salah satu syarat dalam mengkoordinasikan kedua simpang adalah fase antar simpang sama. Perencanaan fase baru terdapat pada Gambar 7 dan Gambar 8.
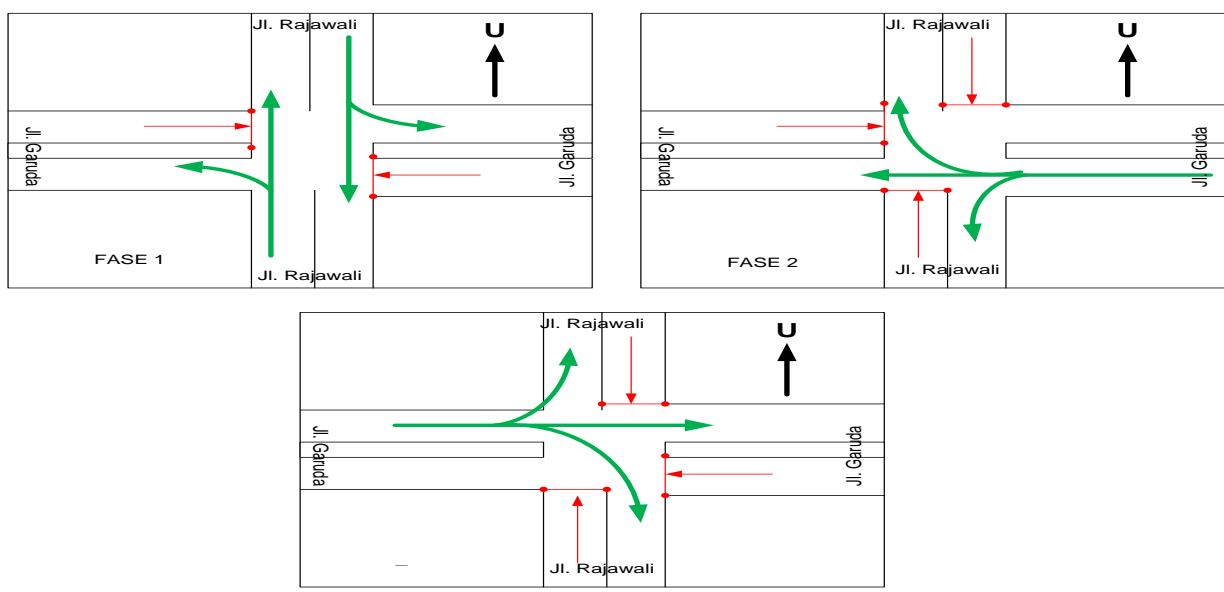

Gambar 7. Simpang I Menjadi 3 fase
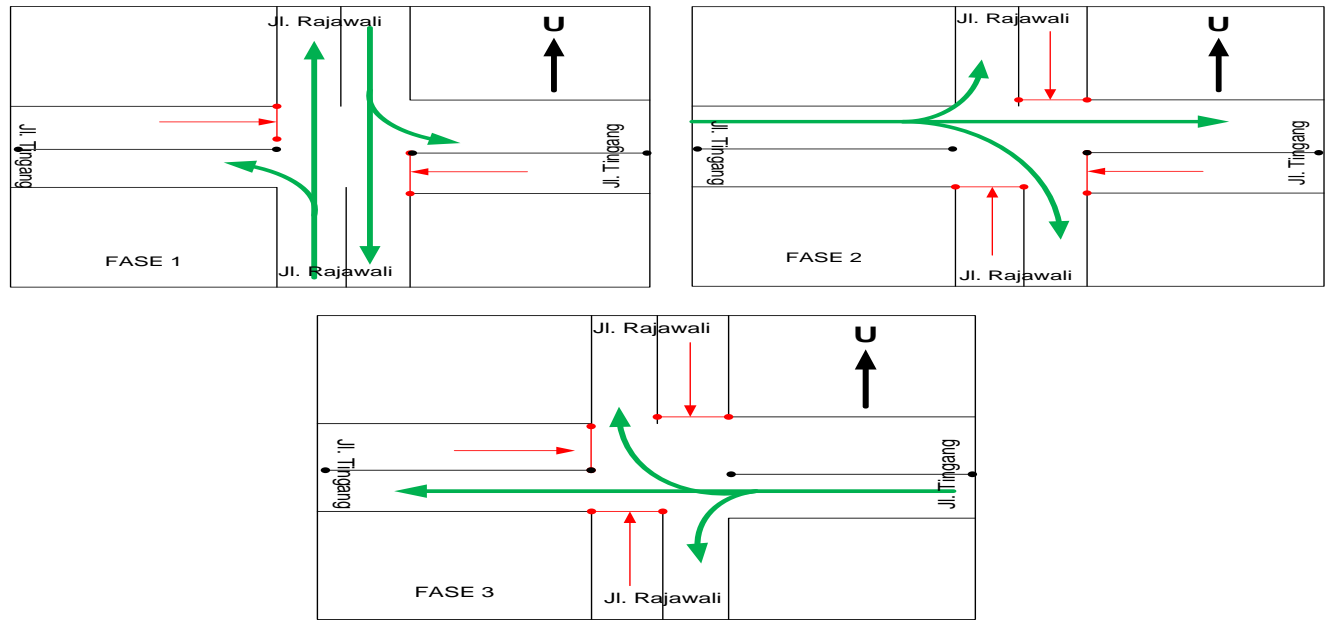

Gambar 8. Simpang II Menjadi 3 Fase

Perubahan pola fase dari 4 fase menjadi 3 fase pada Simpang I dan Simpang II secara langsung mengakibatkan perubahan arus lalu lintas, dimana pada pola 3 fase arus lalu lintas dari kaki simpang arah utara dan selatan bergerak bersamaan ketika mendapatkan sinyal lampu hijau. Hal ini tentunya sangat berbeda dengan pola 4 fase dimana pada setiap kaki simpang mendapatkan sinyal hijau secara bergiliran. Lebih jelasnya pola perubahan arus lalu lintas terdapat pada Gambar 9 dan Gambar 10. 


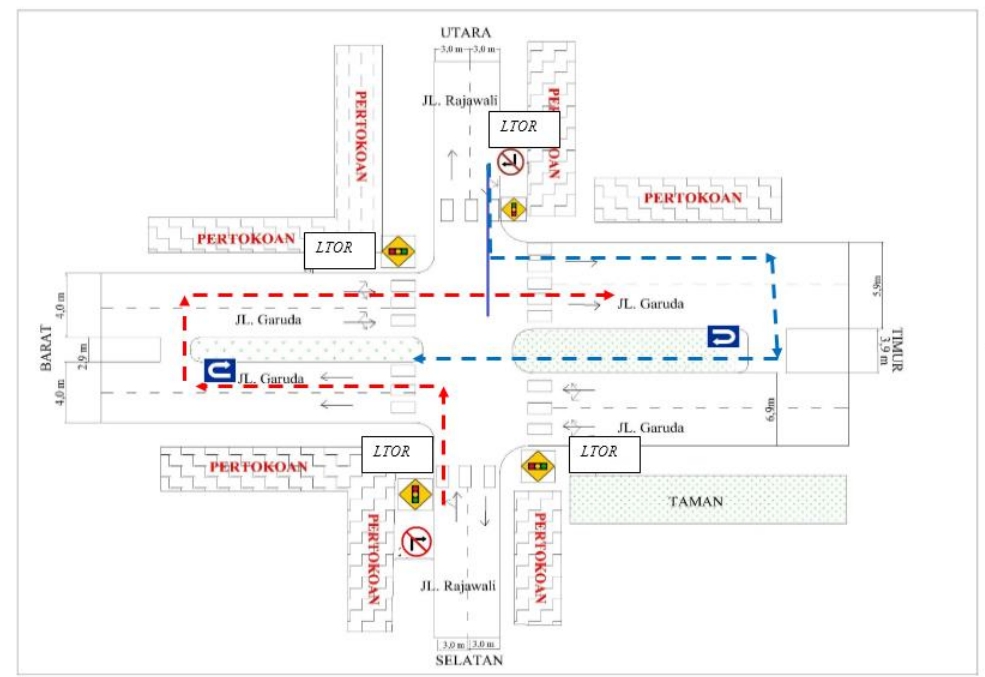

Gambar 9. Simulasi Arus Lalu Lintas Perubahan Simpang I

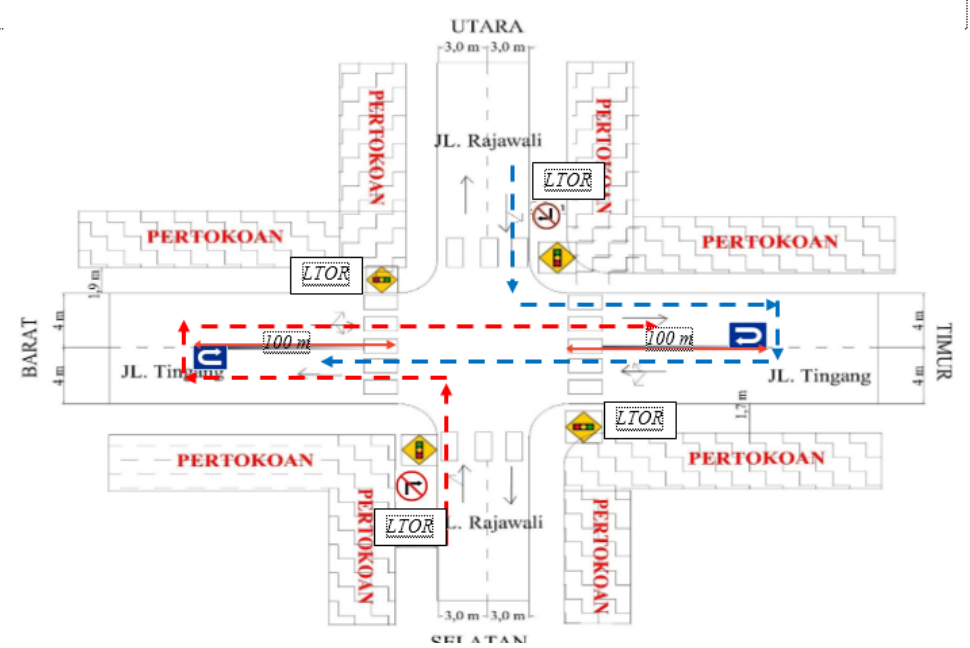

Gambar 10. Simulasi Perubahan Arus Simpang II

Larangan belok kanan pada arah utara dan selatan di kedua simpang mengakibatkan arus lalu lintas yang ingin belok kanan harus dipindahkan atau dicarikan jalur alternatif, sehingga arus lalu lintas belok kanan tidak menambah beban kapasitas pada kaki simpang utara dan selatan. Alternatif yang diterapkan untuk memindahkan arus lalu lintas belok kanan yaitu dengan menerapkan belok kiri langsung (LTOR) pada setiap kaki simpang serta membuat arah putar balik kendaraan (U-TRUN) pada kaki simpang arah timur dan barat, sehingga arus lalu lintas belok kanan dapat terlayani. Khusus untuk kaki simpang arah timur dan barat pada simpang II karena tidak ada trotoar pemisah jalur maka diperlukan tambahan pembatas atau penutup jalan portable (barrier) sepanjang 100 meter dari as lebar kaki simpang, hal ini disebabkan agar arus lalu lintas arah putar balik diberikan ruang untuk putar balik.

b. Tahap perencanaan waktu siklus baru.

Berdasarkan dari panduan Manual Kapasitas Jalan Indonesia (MKJI, 1997) tentang waktu siklus yang disarankan untuk pengaturan dengan 3 fase yaitu antara 50 - 100 detik, Lebih jelasnya terdapat pada Tabel 6 . 
Tabel 6. Waktu Siklus Baru

\begin{tabular}{cccc}
\hline \multirow{2}{*}{ No. } & \multirow{2}{*}{ Uraian } & \multicolumn{2}{c}{ Waktu Siklus (detik) } \\
& & Simpang I & Simpang II \\
\hline 1. & Alternatif ke -1 & 50 & 50 \\
2. & Alternatif ke -2 & 60 & 50 \\
3. & Alternatif ke -3 & 50 & 60 \\
\hline
\end{tabular}

c. Tahap koordinasi sinyal.

Dalam perencanaan koordinasi sinyal digunakan waktu tempuh ratarata hasil observasi langsung dilapangan. Dari hasil obeservasi diperoleh waktu tempuh rata-rata antara kedua simpang selama 56 detik. Lebih jelas diagram waktu koordinasi sinyal dapat dilihat pada Gambar 11, Gambar 12 dan Gambar 13.

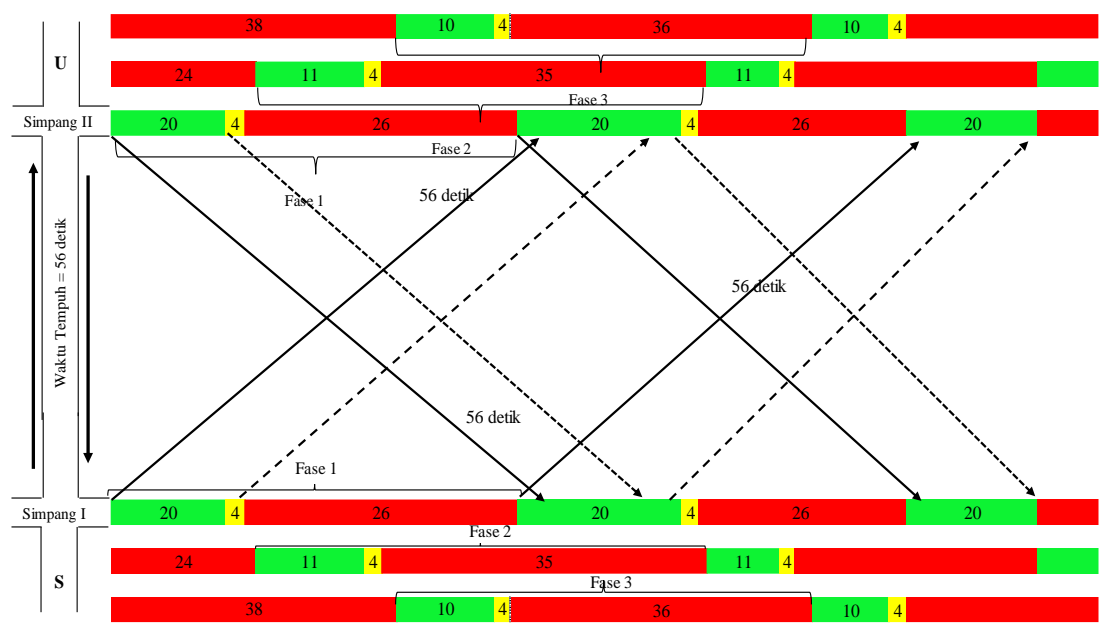

Gambar 11. Diagram Waktu Koordinasi Sinval Alternatif 1

Pada alternatif ke-1 waktu siklus pada Simpang I dan Simpang II dibuat sama yaitu selama 50 detik, sehingga akan terjalin koordinasi sinyal dari Simpang I ke Simpang II dan Simpang II ke Simpang I.

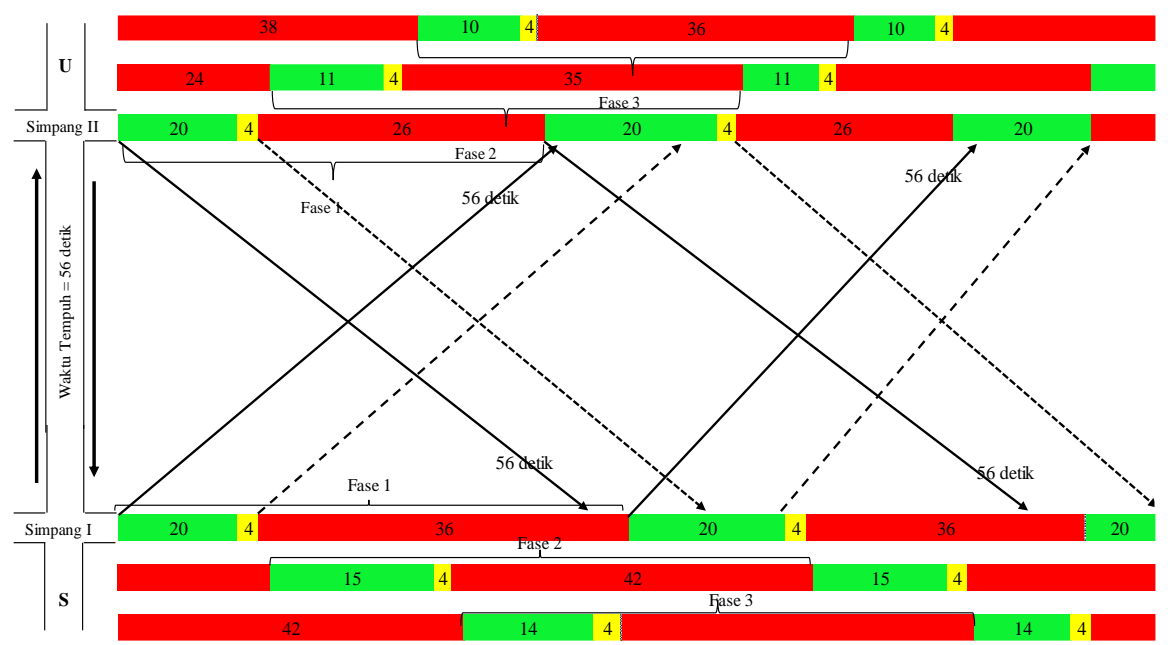

Gambar 12. Diagram Waktu Koordinasi Sinval Alternatif 2

Pada alternatif ke-2 waktu siklus pada Simpang I selama 60 detik dan Simpang II selama 50 detik sehingga koordinasi sinyal akan terjalan pada 
Simpang II ke Simpang I tidak terjadi

koordinasi sinyal.

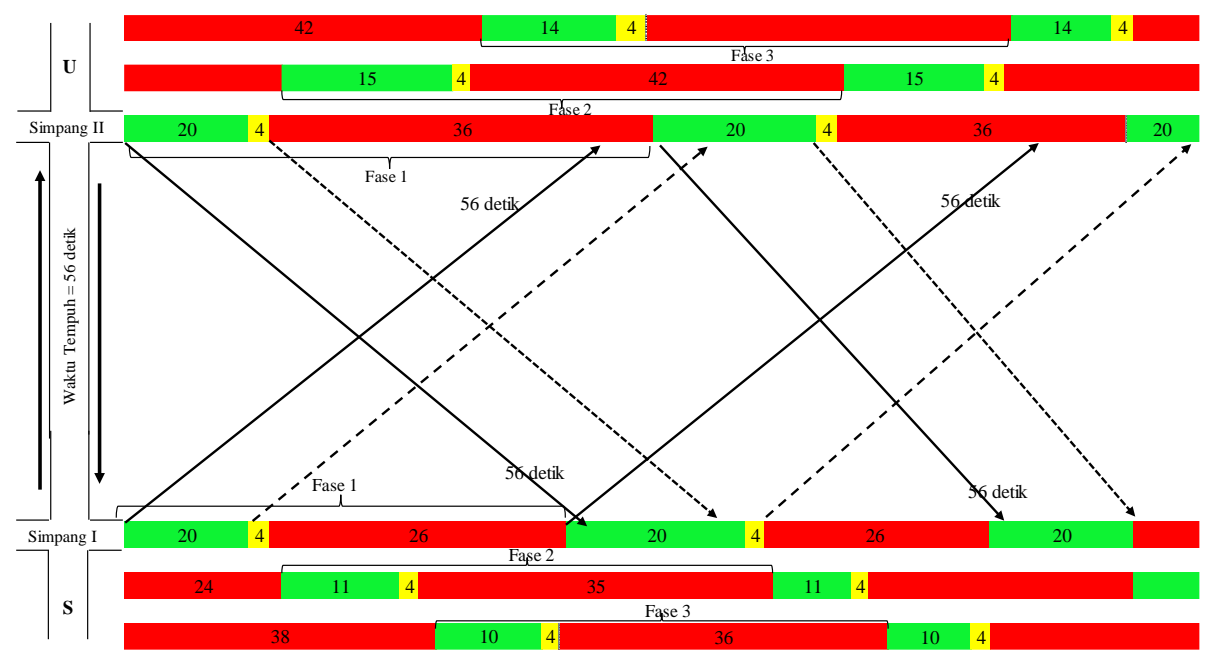

Gambar 13. Diagram Waktu Koordinasi Sinval Alternatif 3

Alternatif ke-3 waktu siklus pada Simpang I selama 50 detik sedangkan pada Simpang II selama 60 detik, sehingga koordinasi sinyal hanya terjadi pada Simpang II menuju Simpang I kemudian dari Simpang I menuju Simpang II tidak terjadi koordinasi sinyal.

d. Evaluasi kinerja simpang bersinyal terkoordinasi.

Evaluasi kinerja simpang bersinyal terkoordinasi menggunakan bantuan perangkat lunak KAJI Versi 1.0, hal ini dilakukan agar mempermudah dalam melakukan perhitungan perubahan fase, belok kiri jalan terus (LTOR), serta manajemen pengaturan simpang lainnya. Hasil evaluasi kinerja simpang bersinyal terkoordinasi pada peak siang terdapat pada Tabel 7.

Tabel 7. Kinerja Simpang Bersinyal Terkoodinasi

\begin{tabular}{|c|c|c|c|c|c|c|c|c|c|c|}
\hline \multirow[b]{2}{*}{$\begin{array}{c}\text { Tahap } \\
\text { Kinerja }\end{array}$} & \multicolumn{5}{|c|}{$\begin{array}{c}\text { Kondisi Simpang I } \\
\text { (rata-rata) }\end{array}$} & \multicolumn{5}{|c|}{$\begin{array}{c}\text { Kondisi Simpang II } \\
\text { (rata-rata) }\end{array}$} \\
\hline & $\begin{array}{c}C \\
(\text { detik) }\end{array}$ & $D S$ & $\underset{\text { (meter) }}{Q L}$ & $\begin{array}{c}D \\
(\mathrm{dtk} / \\
\text { smp) }\end{array}$ & ITP & $C$ (detik) & $D S$ & $\underset{\text { (meter) }}{Q L}$ & $\begin{array}{c}D \\
(\mathrm{dtk} / \\
\text { smp) }\end{array}$ & ITP \\
\hline $\begin{array}{c}\text { Eksisting peak } \\
\text { siang (11.00 - } \\
13.00)\end{array}$ & 92 & 0,878 & 111 & 78,79 & $\mathrm{~F}$ & 103 & 0,765 & 91 & 39,74 & $\mathrm{D}$ \\
\hline $\begin{array}{c}\text { Alternatif ke-1 } \\
\text { Terkoordinasi } \\
\text { antara SP.I ke } \\
\text { SP.II dan SP.II } \\
\text { ke SP.I }\end{array}$ & 50 & 0,833 & 42 & 27,28 & D & 50 & 0,875 & 26 & 30,30 & $\mathrm{D}$ \\
\hline $\begin{array}{c}\text { Alternatif ke-2 } \\
\text { Terkoordinasi } \\
\text { antara SP.I ke } \\
\text { SP.II }\end{array}$ & 60 & 1,856 & 98 & 482,1 & $\mathrm{~F}$ & 50 & 0,875 & 26 & 30,30 & $\mathrm{D}$ \\
\hline $\begin{array}{l}\text { Alternatif ke-3 } \\
\text { Terkoordinasi } \\
\text { antara SP.II ke } \\
\text { SP.I }\end{array}$ & 50 & 0,894 & 28 & 26,53 & $\mathrm{D}$ & 60 & 0,823 & 40 & 36,51 & $\mathrm{D}$ \\
\hline
\end{tabular}


Dari ketiga alternatif tersebut dapat dilihat bahwa alternatif ke-1 memiliki perubahan nilai tundaan yang lebih baik, sehingga menggunakan alternatif ke-1 untuk perencanaan sinyal baru lebih efektif. Pada Simpang I menggunakan alternatif ke-1 dapat menurunkan nilai tundaan eksisting sebanyak 51,51 detik/smp atau sebesar $65,4 \%$ dan nilai tingkat pelayanan simpang berubah menjadi D, sedangkan di Simpang II nilai tundaan eksisting dapat diturunkan sebanyak 17,11 detik/smp atau sebesar 36,1\% dan nilai tingkat pelayanan simpang menjadi D.

e. Perubahan geometrik simpang
Berdasarkan Peraturan Menteri Perhubungan Nomor 96 tahun 2015 tentang Pedoman Pelaksanaan Kegiatan Manajemen dan Rekayasa Lalu Lintas, bahwa pelayanan pada persimpangan untuk jalan kolektor sekurangkurangnya bernilai B.

Perubahan geometrik simpang berupa pelebaran kaki tiap simpang mengacu pada Standar Perencanaan Geometrik Untuk Jalan Perkotaan yang diterbitkan oleh Direktorat Pembinaan Jalan Kota Bina Marga tahun 1992, bahwa pelebaran kaki simpang maksimal sebesar 3,25 meter. Pelebaran geometrik simpang pada Tabel 8.

Tabel 8. Pelebaran Geometrik Simpang

\begin{tabular}{cccccccc}
\hline \multirow{2}{*}{$\begin{array}{c}\text { Lokasi } \\
\text { Pendekat }\end{array}$} & \multicolumn{3}{c}{ Lebar Pendekat Eksisting } & \multicolumn{3}{c}{ Lebar Pendekat Pelebaran } \\
& $\begin{array}{c}\mathrm{W}_{\mathrm{A}} \\
(\mathrm{m})\end{array}$ & $\begin{array}{c}\mathrm{W}_{\text {masuk }} \\
(\mathrm{m})\end{array}$ & $\begin{array}{c}\mathrm{W}_{\text {keluar }} \\
(\mathrm{m})\end{array}$ & $\begin{array}{c}\mathrm{W}_{\mathrm{A}} \\
(\mathrm{m})\end{array}$ & $\begin{array}{c}\mathrm{W}_{\text {masuk }} \\
(\mathrm{m})\end{array}$ & $\begin{array}{c}\mathrm{W}_{\text {keluar }} \\
(\mathrm{m})\end{array}$ \\
\hline \multirow{3}{*}{ Simpang I I } & Utara & 3,0 & 3,0 & 3,0 & 5,0 & 5,0 & 5,0 \\
& Timur & 6,9 & 6,0 & 4,0 & 7,0 & 7,0 & 5,0 \\
& Selatan & 3,0 & 3,0 & 3,0 & 5,0 & 5,0 & 5,0 \\
& Barat & 4,0 & 4,0 & 5,9 & 5,0 & 5,0 & 7,0 \\
\hline \multirow{3}{*}{ Simpang II } & Utara & 3,0 & 3,0 & 3,0 & 5,0 & 5,0 & 5,0 \\
& Timur & 4,0 & 4,0 & 4,0 & 5,0 & 5,0 & 5,0 \\
& Selatan & 3,0 & 3,0 & 3,0 & 5,0 & 5,0 & 5,0 \\
& Barat & 4,0 & 4,0 & 4,0 & 5,0 & 5,0 & 5,0 \\
\hline
\end{tabular}

Setelah perubahan pada geometrik simpang dilakukan, kemudian dilanjutkan analisis kinerja simpang dengan kondisi pada alternatif 1 . Hasilnya terdapat pada Tabel 9.

Tabel 9. Kinerja Simpang Pada Alternatif 1 Setelah Perubahan Geometrik

\begin{tabular}{|c|c|c|c|c|c|c|c|c|c|c|}
\hline \multirow[b]{2}{*}{ Tahap Kinerja } & \multicolumn{5}{|c|}{ Kinerja Simpang I } & \multicolumn{5}{|c|}{ Kinerja Simpang II } \\
\hline & $\begin{array}{c}C \\
(\text { detik) }\end{array}$ & $D S$ & $\underset{\text { (meter) }}{Q L}$ & $\begin{array}{c}D \\
(\mathrm{dtk} / \\
\text { smp) }\end{array}$ & ITP & $\begin{array}{c}C \\
(\text { detik) }\end{array}$ & $D S$ & $\underset{\text { (meter) }}{Q L}$ & $\begin{array}{c}D \\
(\mathrm{dtk} / \\
\text { smp) }\end{array}$ & ITP \\
\hline $\begin{array}{c}\text { Alternatif ke-1 } \\
\text { Terkoordinasi antara } \\
\text { SP.I ke SP.II dan } \\
\text { SP.II ke SP.I }\end{array}$ & 50 & 0,833 & 42 & 27,28 & $\mathrm{D}$ & 50 & 0,875 & 26 & 30,30 & $\mathrm{D}$ \\
\hline $\begin{array}{l}\text { Kinerja Perubahan } \\
\text { Geometrik Simpang }\end{array}$ & 50 & 0,463 & 12 & 14,40 & B & 50 & 0,436 & 8 & 12,85 & B \\
\hline
\end{tabular}

\section{KESIMPULAN}

Dari hasil analisis yang dilakukan dan solusi yang telah diterapkan terdapat beberapa kesimpulan. Sekaligus untuk menjawab perumusan masalah yang sudah ditetapkan, disimpulkan bahwa:

1. Kinerja kedua simpang pada kondisi eksisting di waktu sibuk pagi, waktu sibuk siang dan waktu sibuk sore dapat diketahui kedua simpang tersebut memiliki tingkat pelayanan yang 
buruk. Kedua simpang bersinyal pada ruas Jalan Rajawali juga belum terjadi terkoordinasi, hal ini dapat dilihat dari Simpang I dan Simpang II tidak memiliki waktu siklus yang sama ataupun kelipatannya.

2. Koordinasi sinyal antara Simpang I dan Simpang II dilakukan dengan menetapkan waktu siklus baru dan fase baru. Pada kedua simpang fase eksisting yaitu 4 fase kemudian diganti menjadi 3 fase, diketahui waktu tempuh antara simpang I dan simpang II selama 56 detik. Waktu siklus untuk koordinasi sinyal mengambil alternatif ke-1 dari tiga alternatif waktu siklus terkoordinasi yaitu selama 50 detik pada Simpang I dan 50 detik pada Simpang II. Pada Simpang I menggunakan alternatif ke-1 dapat menurunkan nilai tundaan eksisting sebanyak 51,51 detik/smp atau sebesar $65,4 \%$ dan nilai tingkat pelayanan simpang berubah menjadi $D$, sedangkan di Simpang II nilai tundaan eksisting dapat diturunkan sebanyak 17,11 detik/smp atau sebesar 36,1\% dan nilai tingkat pelayanan simpang menjadi D.

3. Pada Simpang I dan Simpang II disarankan menggunakan pengaturan fase baru dengan menggunakan 3 fase serta menggunakan waktu siklus terkoordinasi.

4. Berdasarkan Peraturan Menteri Perhubungan Nomor 96 tahun 2015 tentang Pedoman Pelaksanaan Kegiatan Manajemen dan Rekayasa Lalu Lintas, bahwa tingkat pelayanan pada persimpangan untuk jalan kolektor sekurang-kurangnya bernilai B. maka untuk mencapai nilai tingkat pelayanan $\mathrm{B}$ diperlukan perubahan geometrik simpang berupa pelebaran jalan pada kaki simpang, sehingga tingkat pelayanan simpang dapat berubah menjadi $\mathrm{B}$.

5. Diharapkan kepada Pemerintah Daerah setempat agar membuat sistem pengontrolan APILL terpusat atau Area Traffic Control Sistem (ATCS) sehingga pengaturan siklus simpang dapat dikendalikan sesuai dengan kondisi lalu lintas langsung dari pusat control APILL.

\section{DAFTAR RUJUKAN}

Departemen Pekerjaan Umum (1997), Manual Kapasitas Jalan Indonesia, Direktorat Jenderal Bina Marga, Jakarta.

Direktorat Pembinaan Jalan Kota (1992), Standar Perencanaan Geometrik Untuk Jalan Perkotaan, Direktorat Jenderal Bina Marga, Jakarta.

James, H. Banks, (2002), Introduction to Transportation Engineering, second edition, San Diego, State University.

Kristy, Jotin C. Dan Lall, Kent B., (2003), Dasar - Dasar Rekayasa Transportasi Jilid 1, Erlangga, Jakarta.

Kristy, Jotin C. Dan Lall, Kent B., (2006), Dasar - Dasar Rekayasa Transportasi Jilid 2, Erlangga, Jakarta.

Peraturan Pemerintah Republik Indonesia Nomor 32 Tahun 2011 tentang Manajemen dan Rekayasa Lalu Lintas, Jakarta.

Peraturan Menteri Perhubungan Republik Indonesia Nomor 96 Tahun 2015 tentang Pedoman Pelaksanaan Kegiatan Manajemen dan Rekayasan Lalu Lintas, Jakarta.

Radam, Iphan F., (2014), Rekayasa Lalu Lintas, Bahan Ajar, Cetakan Kedua, Universitas Lambung Mangkurat, Banjarmasin.

Shane, Mc.W.R and Roess, R.P., (1990), Traffic Engineering, New Jersey:Printice Hall Inc.

Tamin, Ofyar Z., (2000), Perencanaan dan Permodelan Transportasi, Institut Teknologi Bandung, Bandung.

Taylor, Michael, Dan Young, William, (1996), Understanding Traffic System, Sydney, Avebury Technical.

Undang - Undang Republik Indonesia Nomor 22 Tahun 2009 tentang Lalu Lintas dan Angkutan Jalan, Jakarta. 
KINERJA KOORDINASI SIMPANG BERSINYAL JALAN RAJAWALI - JALAN GARUDA (SIMPANG I)

JALAN RAJAWALI - JALAN TINGANG (SIMPANG II) KOTA PALANGKA RAYA

Muhammad Ikhsan Sidiq

Oglesby, C.H. dan Hicks, R.G., (1999),

Teknik Jalan Raya Jilid 1, Jakarta,

Erlangga. 